
zonafranca
Gen:
CENTRO DE ESTUDIOS
INTERDISCIPLINARIOS SOBRE MUJERES
T1G MAESTRIA "PODER Y SOCIEDAD

\title{
"Que sea ley". Producciones audiovisuales colaborativas en torno a la Campaña Nacional por el Derecho al Aborto Legal, Seguro y Gratuito
}

\author{
Claudia Laudano* \\ Julia Kratje ** \\ Alejandra Aracri *** \\ Yamila Balbuena ***
}

\section{Resumen}

El objetivo de este artículo es analizar producciones audiovisuales en torno a los debates parlamentarios de 2018 sobre el Proyecto de Ley de Interrupción

\footnotetext{
* Instituto de Investigaciones en Humanidades y Ciencias Sociales (UNLP - CONICET). Facultad de Humanidades y Ciencias de la Educación. Universidad Nacional de La Plata - Argentina. Contacto: claudano@fahce.unlp.edu.ar
}
** Instituto interdisciplinario de Estudios de Género (UBA - CONICET) - Consejo Nacional de Investigaciones Científicas y Técnicas. Facultad de Filosofía y Letras Universidad de Buenos Aires. Contacto: juliakratje@yahoo.com.ar

*** Instituto de Investigaciones en Humanidades y Ciencias Sociales (UNLP - CONICET). Facultad de Humanidades y Ciencias de la Educación. Universidad Nacional de La Plata - Argentina. Contacto: alejandraaracri@gmail.com

**** Instituto de Investigaciones en Humanidades y Ciencias Sociales (UNLP - CONICET). Facultad de Humanidades y Ciencias de la Educación. Universidad Nacional de La Plata Argentina. Contacto: yamilabalbuena2003@gmail.com

Laudano, Claudia; Kratje Julia; Aracri, Alejandra; Balbuena, Yamila. "Que sea ley'. Producciones audiovisuales colaborativas en torno a la Campaña Nacional por el Derecho al Aborto Legal, Seguro y Gratuito" en Zona Franca. Revista del Centro de estudios Interdisciplinario sobre las Mujeres, y de la Maestría poder y sociedad desde la problemática de Género, №28, 2020 pp. 2249. ISSN, 2545-6504 Recibido: 1 de agosto 2020; Aceptado: 24 de noviembre 2020

Revista Zona Franca- Centro de estudios interdisciplinario sobre las mujeres (CEIM)- Maestría poder y sociedad desde la problemática de género (MG), Rosario, Argentina. ISSN, 2545-6504 http://zonafranca.unr.edu.ar/index.php/ZonaFrancal Número 28 (2020). 
Voluntaria del Embarazo, realizadas por la Campaña Nacional por el Derecho al Aborto Legal, Seguro y Gratuito o de manera colaborativa por agrupaciones que integran La Campaña o que apoya(ro)n su reclamo, tales como Católicas por el Derecho a Decidir, Actrices Argentinas, Mujeres Audiovisuales de Argentina y Red de Profesionales de la Salud por el Derecho a Decidir. Desde el cruce interdisciplinario de teorías feministas, retórica de la imagen y estudios audiovisuales, entendemos que las piezas comunicacionales que circularon a través de redes sociales constituyen un territorio de intervención decisiva en el universo simbólico contemporáneo. El trabajo se inscribe en una investigación colectiva más amplia sobre modalidades de apropiación de tecnologías de la comunicación y la información por parte de agrupaciones feministas de la Argentina, tomando en consideración su activismo digital y las tradicionales acciones en el espacio público!.

Palabras clave: aborto; audiovisuales; movimiento feminista; Tic.

"Que sea ley". Collaborative audiovisual productions around the Campaña Nacional por el Derecho al Aborto Legal, Seguro y Gratuito

\section{Abstract}

The goal of this article is to analyze audiovisual productions made collaboratively by the Campaña Nacional por el Derecho al Aborto Legal, Seguro y Gratuito, and groups linked in different ways to the Campaña (such as Católicas por el Derecho a Decidir, Actrices Argentinas, Mujeres Audiovisuales de Argentina and Red de Profesionales de la Salud por el Derecho a Decidir) around the 2018 parliamentary debates of the voluntary termination of pregnancy bill. From the overlapping approaches among feminist theories, image rethoric and audiovisual studies, the audiovisual materials spread by social media constitute a territory of decisive intervention in the contemporary symbolic universe. The work is part of a broader collective research on modalities of appropriation of communication and information technologies by feminist groups in Argentina, taking into consideration their digital activism and traditional actions in the public sphere.

Keywords: Abortion; audiovisuals; ITC.

' El trabajo se enmarca en el Proyecto de Investigación y Desarrollo del Ministerio de Educación de la Nación H817 "Feminismos contemporáneos y TICs. Modalidades de apropiación de tecnologías de comunicación e información por parte de grupos feministas de Argentina", en ejecución en IdIHCS-FaHCE-UNLP-CONICET. Claudia Laudano es directora, Julia Kratje, Alejandra Aracri y Yamila Balbuena son integrantes.

Revista Zona Franca- Centro de estudios interdisciplinario sobre las mujeres (CEIM)- Maestría poder y sociedad desde la problemática de género (MG), Rosario, Argentina. ISSN, 2545-6504 http://zonafranca.unr.edu.ar/index.php/ZonaFranca| Número 28 (2020).

Página 23 


\section{Introducción}

Comencemos con un breve zapping por distintos medios y canales. "No aborte, Mirtha", expresó Jorgelina Aruzzi ("Actriz...madre...argentina...desequilibradamente libriana", según su propia descripción en la cuenta de Twitter) el 10 de junio de 2018, durante el programa Almorzando con Mirtha Legrand. "No aborte si está en contra", subrayó ante la opinión negativa de la conductora, a tres días del tratamiento del Proyecto de Ley de Interrupción Voluntaria del Embarazo en la Cámara de Diputados. La ironía del episodio, extensamente comentado en redes sociales, provenía de la sorpresa por el hecho de que una invitada (en este caso, además, apenas famosa) pusiera en un lugar absurdo a la diva nonagenariall.

Un retrato de Lucrecia Martel junto a la proposición: "La mujer tiene derecho a eliminar una vida humana. Sí, señor" fue utilizado, como una cita de autoridad tergiversada y descontextualizada, por sectores contrarios a la legalización del aborto demonizando a la cineasta, cuyas críticas a la familia nuclear, al sexismo, a la religión alcanzaron notoriedad en la escena mediática tras el estreno de Zama, su cuarto largometraje. En efecto, Martel había publicado una carta abierta manifestando su apoyo a la Ley, desde una iniciativa surgida en un grupo de WhatsApp, donde enunciaba su disentimiento con algunos funcionarios que se oponían a la ampliación de derechos"'!.

En este contexto, Jem \& the Holograms (unos dibujos animados de Estados Unidos creados en 1985, que tuvieron difusión en la televisión argentina en la década siguiente), Daria (una serie animada producida por MTV a fines de los noventa), el maestro Yoda (personaje de Star Wars), Matilda (la niña que

\footnotetext{
"Recuperado de: https://cutt.ly/Gd7AtLg Fecha de consulta: 4 de julio de 2020.

III Los pronunciamientos de Lucrecia Martel sobre este tema se pueden consultar en: https://www.pagina12.com.ar/128416-carta-abierta-de-lucrecia-martel-por-el-aborto-legal http://www.agenciapacourondo.com.ar/generos/aborto-legal-carta-abierta-de-lucrecia-martelurtubey-y-los-legisladores-saltenos
}

Revista Zona Franca- Centro de estudios interdisciplinario sobre las mujeres (CEIM)- Maestría poder y sociedad desde la problemática de género (MG), Rosario, Argentina. ISSN, 2545-6504 http://zonafranca.unr.edu.ar/index.php/ZonaFrancal Número 28 (2020). Página 24 
protagoniza la película homónima dirigida por Danny DeVito en 1997), Campanita (el hada creada por J. M. Barrie, que se convirtió en un personaje entrañable de Peter Pan según la versión de Disney), entre otros, aparecieron vistiendo pañuelos verdes en pancartas e ilustraciones. Del variopinto repertorio de reapropiaciones de personajes ficcionales, quizá la intervención con mayores repercusiones fue la performance impulsada por el grupo Periodistas Argentinas, basada en la serie El cuento de la criada (que Netflix produjo a partir de la novela de Margaret Atwood), cuya denuncia contra la imposición de la maternidad no deseada circuló en redes sociales bajo el hashtag \#NoSomosCriadas.

Contradicciones, escraches, réplicas, manifiestos, consignas: la multiplicidad de discursos alrededor de personalidades e íconos de la cultura mediática, en particular de la industria audiovisual, expone la vasta mediatización alcanzada por el debate. En esta dirección, desde el cruce interdisciplinario de teorías feministas y retórica audiovisual (Pollock, 2013; Mulvey, 2007; de Lauretis, 1996; Kuhn, 1991; Silverman, 1988, Laudano y Kratje, 2018), cuyos aportes específicos se indican a lo largo del trabajo, nos interesa explorar un conjunto de videos alrededor de los debates parlamentarios de 2018 sobre el Proyecto de Ley de Interrupción Voluntaria del Embarazo realizados por la Campaña Nacional por el Derecho al Aborto Legal, Seguro y Gratuito (en adelante, La Campaña) o de manera colaborativa por agrupaciones que integran o que apoya(ro)n su reclamo, tales como Católicas por el Derecho a Decidir, Actrices Argentinas, Mujeres Audiovisuales de Argentina y Red de Profesionales de la Salud por el Derecho a Decidir.

Tras unas intervenciones vigorosas en redes sociales con los hashtags \#AbortoLegalYa y \#Soyfeminista, la participación de feministas en programas televisivos de amplia audiencia durante el verano de 2018 (Laudano, 2018), junto a los pañuelazos federales impulsados por La Campaña y la movilización multitudinaria del \#8M durante el II Paro Internacional de Mujeres, entre abril y agosto se realizaron las sesiones informativas y las discusiones en ambas

Revista Zona Franca- Centro de estudios interdisciplinario sobre las mujeres (CEIM)- Maestría poder y sociedad desde la problemática de género (MG), Rosario, Argentina. ISSN, 2545-6504 http://zonafranca.unr.edu.ar/index.php/ZonaFranca| Número 28 (2020).

Página 25 
cámaras legislativas del Congreso de la Nación. En síntesis, el proyecto por la legalización del aborto fue aprobado en la Cámara de Diputados el 14 de junio y desaprobado, por una exigua diferencia, el 8 de agosto en la Cámara de Senadores. Durante esos meses, el feminismo, en articulación transversal con distintos sectores sociales que se sintieron interpelados por el reclamo de la legalización del aborto, devino "marea verde". Décadas de intensa lucha en democracia tras este derecho (Durand y Gutiérrez, 1998, Bellucci, 2014), confluyeron en una cartografía intergeneracional (Elizalde y Matteo, 2018, Sutton, 2020), que activó memorias discursivas y concertó acciones desde una singular polifonía de voces.

Teniendo en cuenta el recorrido preliminar, este trabajo examina estrategias retóricas, discursivas y estéticas en torno a la puesta en escena de argumentos movilizados por agrupaciones a través de videos que circularon por redes sociales (especialmente, Twitter, Facebook y YouTube). Esta perspectiva implica considerar que las producciones audiovisuales constituyen un campo de disputa con respecto al género, entendido como el producto de tecnologías sociales y de discursos institucionalizados, de prácticas críticas y de la vida cotidiana. Siguiendo a Teresa de Lauretis, el género no refiere a una propiedad de los cuerpos, sino a los "efectos producidos en los cuerpos, los comportamientos y las relaciones sociales" (1996: 8). El discurso audiovisual, en esta línea, no consiste simplemente en un mecanismo de representación de visiones de la realidad social a través de imágenes, que tendería a reproducir la representación de la mujer como imagenespectáculo y objeto ofrecido a la contemplación, sino una actividad semiótica. Los videos que en este artículo indagamos, suponen la producción y la reproducción de significados y valores en los planos social y subjetivo, y a la vez exponen la inscripción del sujeto en la ideología, "que produce efectos de significado y percepción, auto-imágenes y posiciones subjetivas para todos los implicados, realizadores y receptores", tal como afirma de Lauretis (1992: 63).

Revista Zona Franca- Centro de estudios interdisciplinario sobre las mujeres (CEIM)- Maestría poder y sociedad desde la problemática de género (MG), Rosario, Argentina. ISSN, 2545-6504 http://zonafranca.unr.edu.ar/index.php/ZonaFrancal Número 28 (2020). 
Así, el análisis toma como guía las siguientes preguntas generales: ¿Cuáles son las principales posiciones enunciativas en cuanto a la mirada y la escucha? ¿De qué modos se presentan las tramas narrativas y argumentativas? ¿Qué afectos se materializan? ¿Cómo se construye el campo de fuerzas a partir de los elementos visuales y sonoros que definen los audiovisuales? El interés por explorar discursos audiovisuales supone reconocer que constituyen un territorio relevante para las intervenciones feministas contemporáneas, tal como afirma Annette Kuhn: "Una de las mayores contribuciones teóricas del movimiento feminista ha sido su insistencia en el valor significativo de los factores culturales" (1991: 18). En efecto, siguiendo a Griselda Pollock, "una intervención feminista excede la preocupación local por 'la cuestión femenina' y pone al género en una posición central dentro de los términos de análisis histórico (siempre en conjunto con otras estructuraciones como la clase y la raza, que se influyen mutuamente)" (2013: 37). Se trata, por lo tanto, de aportar a la indagación del género como tecnología social y del audiovisual como tecnología de género, en el marco de la crítica de los modos de representación y de las implicaciones económicas, sociales, políticas y culturales de las imágenes con respecto a la memoria del movimiento de mujeres y del feminismo en la Argentina.

La Campaña Nacional por el Derecho al Aborto Legal, Seguro y Gratuito es una alianza federal que articula acciones para legislar el derecho al aborto desde su formación en 2005 (Anzorena y Zurbriggen, 2013). "Asumimos un compromiso con la integralidad de los Derechos Humanos, y defendemos el derecho al aborto como una causa justa para recuperar la dignidad de las mujeres y con ellas, la de todos los seres humanos", destacan en su sitio web. Está integrada por grupos feministas y de mujeres, organizaciones y personalidades vinculadas a organismos de derechos humanos, sectores académicos y científicos, trabajadoras y trabajadores del ámbito de la salud, sindicatos y movimientos sociales y culturales, redes campesinas y de educación, organizaciones de desocupadas/os y de fábricas recuperadas, grupos estudiantiles, periodistas,

Revista Zona Franca- Centro de estudios interdisciplinario sobre las mujeres (CEIM)- Maestría poder y sociedad desde la problemática de género (MG), Rosario, Argentina. ISSN, 2545-6504 http://zonafranca.unr.edu.ar/index.php/ZonaFranca| Número 28 (2020).

Página 27 
organizaciones LGTTTBIQ+, entre otros. Su lucha por la legalización del aborto se enmarca en una concepción de la democracia como sistema que debe garantizar la justicia social y los derechos humanos, favorecer el acceso a la salud a toda la ciudadanía y brindar el apoyo necesario a quienes decidan interrumpir sus embarazos. En esta dirección, se sostiene el reclamo por la laicidad del Estado frente a un contexto argentino y latinoamericano en el que las iglesias impiden la libre decisión de las personas respecto de su vida sexual y reproductiva. Asimismo, junto con la legalización y la despenalización del aborto, se exige reglamentar la atención del post-aborto, volver efectiva la Ley 25.673 de Salud Sexual y Procreación Responsable, cumplir el Compromiso para la Disminución de la Mortalidad Materna, el Protocolo de Asistencia Humanitaria del Post-aborto y reformar el Código Penal a partir de una consulta popular abierta.

Desde luego, las intervenciones con vistas al debate de la Ley en ambas Cámaras legislativas han sido prolíficas. Es así que, a los fines de este trabajo, nos interesa focalizar el análisis en piezas audiovisuales hechas por La Campaña o en colaboración con ciertos colectivos, dos de ellos integrantes de la coalición, como Católicas por el Derecho a Decidir y Red de Profesionales de la Salud por el Derecho a Decidir, mientras que Actrices Argentinas y Mujeres Audiovisuales de Argentina se sumaron al reclamo por la Ley. Nuestra hipótesis general sostiene que el activismo digital de quienes defienden y apoyan la autonomía, la laicidad y las políticas públicas para la ampliación de derechos sexuales, reproductivos y no reproductivos se dirige a un horizonte amplio de interlocutores, pues los videos no contienen sólo una dimensión polémica que busca replicar argumentos de ciudadanos y de organizaciones contrarios a la legalización del aborto sino que privilegian la incorporación de un público más extenso.

Las imágenes engendran contradicciones en los procesos sociales y subjetivos, ya que el público, a la vez que es interpelado por su narrativa audiovisual, atraviesa los discursos y por eso no se encuentra completamente capturado ni tampoco por fuera de sus estrategias retóricas.Con relación a las

Revista Zona Franca- Centro de estudios interdisciplinario sobre las mujeres (CEIM)- Maestría poder y sociedad desde la problemática de género (MG), Rosario, Argentina. ISSN, 2545-6504 http://zonafranca.unr.edu.ar/index.php/ZonaFranca| Número 28 (2020).

Página 28 
nociones utilizadas para el análisis textual del corpus, resulta productivo incorporar a los estudios feministas sobre cine el marco interpretativo desarrollado por Roland Barthes (1972), quien analiza con base en el modelo del arte de la retórica de Aristóteles la dimensión persuasiva de ciertos argumentos a partir de las imágenes de sí y de los climas físicos que construye el orador (ethos), el punto de vista del mensaje y su codificación (logos) y la delegación o la proyección de pasiones despertadas en el auditorio (pathos). El poder de la imagen y de la palabra reside, precisamente, en la capacidad de conversión, esto es: en la posibilidad de establecer un nexo personal, pasional, con las y los espectadores en la medida en que la retórica depende de la capacidad del orador para adaptarse al público. Retomando la definición aristotélica de la retórica como "arte de extraer de cualquier tema el grado de persuasión que comporta", o como "la facultad de descubrir especulativamente lo que en cada tema puede ser adecuado para persuadir" (Barthes, 1972: 94), la dimensión retórica de las piezas comunicacionales que seleccionamos para este trabajo implica considerar una estética de la obra y una estética del público. Puesto que su ámbito de circulación es el de las redes sociales, donde reina la "verosimilitud", aquello que el público cree posible se transforma en una arena de batalla colectiva por convencer por medio de razonamientos y pruebas lógicas, y conmover a través de pruebas psicológicas, referidas a los caracteres, los tonos, los aires del orador y a las pasiones, los sentimientos y los afectos que se buscan suscitar.

En tal sentido, los argumentos feministas, presentes en las producciones audiovisuales, reelaboran y negocian significados, posiciones enunciativas, presunciones y valores, al tiempo que proponen nuevas coordenadas estéticas y discursivas. Por eso, según se demuestra en este trabajo, examinar una serie de piezas comunicacionales que buscaron convocar a la ciudadanía a manifestarse y lograr adhesiones de actores políticos clave permite identificar formas emergentes del activismo feminista y su poder de interpelación.

Revista Zona Franca- Centro de estudios interdisciplinario sobre las mujeres (CEIM)- Maestría poder y sociedad desde la problemática de género (MG), Rosario, Argentina. ISSN, 2545-6504 http://zonafranca.unr.edu.ar/index.php/ZonaFranca| Número 28 (2020).

Página 29 


\title{
Un reclamo urgente, ecuménico y federal
}

Las primeras intervenciones de Católicas por el Derecho a Decidir, el movimiento autónomo de mujeres católicas constituido como una asociación civil sin fines de lucro en la que participan activistas comprometidas con la defensa de los derechos de las mujeres, se remontan a 1993. Sus acciones por la equidad en las relaciones de género buscan contrarrestar, tal como afirman en su página web, "desde una perspectiva teológica y feminista, los fundamentalismos religiosos"”v. Por medio de sus canales de Twitter, Facebook, YouTube e Instagram publican de manera periódica información sobre educación sexual, anticoncepción y aborto. En efecto, el Tweet fijado el 8 de agosto de 2019 dice lo siguiente: "Hace un año el Senado votaba a favor de la clandestinidad del aborto. Seguimos siendo víctimas de esa decisión, nos niegan un derecho humano. Por Belén, Juana, Lucía, M. Magdalena, Ana María Acevedo, Liliana Herrera. Ni muertas ni presas. \#QueSeaLey \#LaClandestinidadNOseFesteja".

Este Tweet encabeza un video ${ }^{\vee}$ que abre con un texto en letras blancas sobre una textura verdeazulada, que se va desplazando hacia la izquierda a medida que las placas informativas avanzan en absoluto silencio:

\begin{abstract}
"Belén fue condenada injustamente a ocho años de prisión por un abortoespontáneo en Argentina. En 2017, Soledad Deza, abogada de Católicas por el Derecho a Decidir asumió su defensa técnica. Su historia tomó relevancia pública cuando se denunciaron las irregularidades de su caso y la violencia institucional a la que había sido sometida. Personal de salud, policías y fiscales desoyeron los pedidos de Belén y perpetuaron la cadena de vulnerabilidades con prejuicios de género y clase. Luego de meses de movilización popular y habiendo su caso tomado trascendencia
\end{abstract}

IV Recuperado de: http://catolicas.org.ar/catolicas-por-el-derecho-a-decidir-argentina-3/ Fecha de consulta: 22 de enero de 2020.

$\checkmark$ Recuperado de: https://twitter.com/i/status/1159450199900807168 Fecha de consulta: 22 de enero de 2020.

Revista Zona Franca- Centro de estudios interdisciplinario sobre las mujeres (CEIM)- Maestría poder y sociedad desde la problemática de género (MG), Rosario, Argentina. ISSN, 2545-6504 http://zonafranca.unr.edu.ar/index.php/ZonaFrancal Número 28 (2020). 
internacional, Belén recuperó su libertad y finalmente se logró su absolución. 'La libertad de Belén fue una fiesta para todo el movimiento de mujeres y sin dudas su absolución, un acto de justicia' (Soledad Deza). Ni muertas ni presas por abortar. La clandestinidad no salva ninguna vida. \#AbortoLegalYa"

Las únicas imágenes visuales que aparecen en esta producción despojada de marcas de exclamación están incluidas en un video que enfoca brazos alzando pañuelos verdes. Es evidente que la forma de procurar la atención de la audiencia apuesta al efecto que promueve la sustracción del sonido (no hay voces, ni músicas, ni ruidos). La ampliación del silencio favorece la concentración en la lectura. Por cierto, no es usual encontrar tanto contenido textual en este tipo de propuestas comunicacionales. Asimismo, los argumentos están labrados desde un tono jurídico: la construcción de la posición enunciadora de este video apela a un ethos de seguridad arraigada en su saber profesional, ya que se citan palabras de una abogada contando hechos realmente sucedidos.

¿De dónde provienen las figurasde autoridad que definen las coordenadas de los argumentos a favor del derecho al aborto para el caso de Belén, narrado a partir de la placa informativa? Del campo profesional jurídico, del ejercicio de la medicina, de la recuperación de historias de vida y testimonios de mujeres que interrumpieron sus embarazos en la clandestinidad. Al contrario de los discursos elaborados por el sector que integran quienes se oponen a la legalización, que mayormente postula argumentos basados en el valor abstracto de "la vida", que buscan volver tangible por medio de gigantografías de "fetos" representados como si fueran bebés (Laudano, 2012), el activismo feminista enraíza sus premisas en el campo de lo real, desde el que aflora la justificación de sus demandas que apuntan a ideales, como la justicia, la libertad de elección y la autonomía, sostenidos por reclamos concretos y racionales.

En esta línea, en las antípodas del conservadurismo fundamentalista, evitando el uso indiscriminado de fórmulas efectistas, Católicas por el Derecho a

Revista Zona Franca- Centro de estudios interdisciplinario sobre las mujeres (CEIM)- Maestría poder y sociedad desde la problemática de género (MG), Rosario, Argentina. ISSN, 2545-6504 http://zonafranca.unr.edu.ar/index.php/ZonaFranca| Número 28 (2020). 
Decidir remarca la vía lógica de la argumentación para interpelar a sus destinatarios/as: "El 13/6 se vota por \#AbortoLegalYa en Diputados. A los/las legisladores que todavía no se decidieron \#HacelosPensar \#AbortoSinBarreras". Hacer pensar es la principal aspiración de los materiales audiovisuales producidos por este colectivo, de acuerdo al razonamiento: "No es aborto sí o no lo que deben decidir, es \#AbortoLegalOClandestino". Precisamente, con ese hashtag La Campaña marcó tendencia en la conversación de Twitter días antes de la votación, para desplazar la disputa del eje de debate en torno al origen de la vida, tópico predilecto de quienes se oponen a la legalización (Laudano, 2018). Al proceder de algo particular, siguiendo a Barthes, "el exemplum puede tener cualquier dimensión: puede ser una palabra, un hecho, un conjunto de hechos y el relato de esos hechos" (1972: 126): en cuanto al video mencionado, se trata de un exemplum proveniente del campo de lo real que desenvuelve una narrativa sobria y convincente.

El día previo a la votación en el Senado, esta organización difundió un video ${ }^{\mathrm{V}}$, precedido por la expresión: "Senadores y Senadoras: que sea ley", en el que se exploran otras tácticas retóricas: un carnavalito que trae junto a su rítmica musicalidad aires del folklore del noroeste del país suena a lo largo de 52 segundos para acompañar fotos de mujeres sonrientes, con bebés en brazos, vistiendo bufandas y gorros con tonalidades azules, celestes y verdes, imágenes de columnas marchando detrás de la bandera de La Campaña, agitando los pañuelos verdes con una expresión de regocijo y ostentando un gesto de satisfacción, sobre las que se graban las leyendas: "Por una maternidad planificada y deseada", "por nuestra autonomía", "por nuestra libertad", "por nuestro derecho a decidir". Luego, reafirma el eje argumentativo según el cual "la clandestinidad no salva vidas", y lanza una interpelación a quienes estaban en posición de definir con su voto en la Cámara alta: "Basta de hipocresía", en

VI Recuperado de: https://twitter.com/i/status/1026808080007344128 Fecha de consulta: 22 de enero de 2020.

Revista Zona Franca- Centro de estudios interdisciplinario sobre las mujeres (CEIM)- Maestría poder y sociedad desde la problemática de género (MG), Rosario, Argentina. ISSN, 2545-6504 http://zonafranca.unr.edu.ar/index.php/ZonaFrancal Número 28 (2020). 
tipografía blanca sobre fondo negro; junto al slogan tripartito de La Campaña: "Educación sexual para decidir. Anticonceptivos para no abortar. Aborto legal, seguro y gratuito para no morir", resaltado en verde, sobre imágenes del movimiento de mujeres, y al final, multiplicándose en distintos ángulos del cuadro, la palabra: "Ya".

En este segundo video, el uso del exemplum genera un modo persuasivo mediante la inducción, que "procede de algo particular a otra cosa particular mediante la cadena implícita de lo general" (Barthes: 1972: 126), que funciona en un sentido diferente al anterior, pues el relato de acontecimientos históricos adopta un aire que se acerca a la narración de una gesta popular que envuelve el reclamo extensamente difundido a lo largo del territorio nacional.

\section{Con calma y con certeza}

Tras la media sanción lograda en la Cámara de Diputados, la Red de Profesionales de la Salud por el Derecho a DecidirVII, conformada en 2015, difundió una serie de audiovisuales con el hashtag "\#ContasConNosotrxs" por Twitter. En menos de un minuto, como en el video difundido el 26 de junio VIII, médicas y médicos procedentes de distintos puntos del país y con diferentes especializaciones explican cuáles son los beneficios de la legalización del aborto

VII Después del debate en el Senado, cuando a mediados de septiembre el Gobierno Nacional resolvió eliminar el Ministerio de Salud, transformándolo en una Secretaría dependiente del Ministerio de Desarrollo Social de la Nación, esta Red expresó su rechazo y preocupación ante la decisión: "En un contexto de extrema hostilidad y avasallamiento al ejercicio de la autonomía de las mujeres y personas gestantes, ante un reciente rechazo del sector más conservador de la política a la aprobación de la Ley de Interrupción Voluntaria del Embarazo en la Cámara de Senadores, una marcada presencia de grupos antiderechos opuestos a la implementación de la Educación Sexual Integral en las escuelas como herramienta de prevención y autocuidado esenciales para Ixs jóvenes de nuestro país; la transformación del Ministerio de Salud en Secretaría vuelve a dejar expuestos a Ixs profesionales y trabajadorxs de la salud que sí nos encontramos comprometidxs en la garantía de derechos, respetando las normativas legales existentes en todo el país y generando prácticas de atención desde el cuidado, la afectividad y el respeto, a un panorama de incertidumbre, desconcierto y desprotección; aspectos que se traducirán inevitablemente en la calidad de atención que podemos garantizar a toda la población usuaria del sistema público de salud". Recuperado de: https://cutt.ly/fd7SLFO Fecha de consulta: 22 de enero de 2020.

VIII Recuperado de: https://cutt.ly/9d7SKWU Fecha de consulta: 22 de enero de 2020.

Revista Zona Franca- Centro de estudios interdisciplinario sobre las mujeres (CEIM)- Maestría poder y sociedad desde la problemática de género (MG), Rosario, Argentina. ISSN, 2545-6504 http://zonafranca.unr.edu.ar/index.php/ZonaFranca| Número 28 (2020).

Página 33 
para la salud. Los y las profesionales, además de los pañuelos verdes, varias veces también con el violeta feminista, portan sus blancos delantales característicos y aparecen identificados con sus nombres y números de matrículas. "Los costos de las complicaciones de un aborto inseguro son siempre más altos que las prácticas de un aborto seguro", "si se legaliza el aborto, nosotras vamos a respetar tus derechos", "para decidir sobre tu cuerpo, contá con nosotras", "contás con nosotros", "en Córdoba, podés contar con nosotros", "les pedimos a los senadores y a las senadoras que aprueben la Ley de Interrupción Legal del Embarazo".

La pieza comunicacional es sencilla pero eficaz, pues hilvana estas frases enunciadas por profesionales de la salud, que son presentadxs como voces autorizadas para transmitir tranquilidad a las destinatarias. Para ello, el video pone en escena un ambiente relajado: la filmación no transcurre en el interior de hospitales, clínicas o consultorios sino que se desarrolla íntegramente en exteriores, durante un día soleado. Esta escenografía está acompañada por una música muy simple, ejecutada por cuerdas pulsadas, a las que primero se incorpora una batería que refuerza el ritmo de los arpegios y, más adelante, una guitarra eléctrica que otorga dinamismo para que el audiovisual crezca en intensidad, pero sin volverse estridente ni quitarles protagonismo a los argumentos verbales.

Las personas hablan pausadamente, sonrientes, desplegando un ethos de seguridad que busca inspirar confianza en el auditorio. La estrategia en la que se apoya esta imagen de sí es la de convocar una figura del exemplum que Barthes, retomando la retórica de Quintiliano y de Cicerón, llama "el personaje ejemplar" (eikón, imago) para designar a quienes se presentan como encarnación de una virtud. En esta línea, la serie titulada "\#ContasConNosotrxs" se basa en la posición arquetípica que el discurso médico -representado por trabajadores/as del ámbito de la salud: en específico, médicos y médicas- comporta para el público al que

Revista Zona Franca- Centro de estudios interdisciplinario sobre las mujeres (CEIM)- Maestría poder y sociedad desde la problemática de género (MG), Rosario, Argentina. ISSN, 2545-6504 http://zonafranca.unr.edu.ar/index.php/ZonaFranca| Número 28 (2020). 
esos videos se dirigen, que en la sociedad actual constituye un amplio arco de destinatarios.

\section{El grito del corazón}

Antes de la votación en el Senado, el 4 de agosto La Campaña difundió un video ${ }^{\mathrm{X}}$ cuya finalidad, si se presta atención a sus tácticas persuasivas (es decir, tanto al texto como al tono), no apunta a hacer cambiar de opinión a quienes manifiestan defender "las dos vidas" ni tampoco privilegia el vínculo con quienes tienen dudas; más bien, está dirigido a quienes participaron activamente en la concentración frente a la plaza del Congreso, pese a que la leyenda del final exponga: "El pueblo ya eligió; senadoras, senadores, que sea ley, el \#8A seamos millones". El punto de vista no hace prevalecer el ethos de seguridad, como en los casos precedentes, sino que se dirige a conmover (más que a convencer privilegiando argumentos racionales), mediante la reapropiación de memorias discursivas ligadas al valor de la identidad nacional:

"Nos, nos, nos, las ciudadanas del pueblo de la Nación argentina, reunidas en La Campaña por el Derecho al Aborto Legal, Seguro y Gratuito, en Encuentros Nacionales de Mujeres, en asambleas Ni Una Menos, en las calles, en lugares de trabajo, en instituciones educativas, por voluntad y elección de las provincias que la componen, en cumplimiento de pactos preexistentes, con el objeto de constituir la equidad nacional, afianzar la justicia social, consolidar los Derechos Humanos,y promover la autonomía y el bienestar general, y asegurar la libertad para nosotras, para nuestra prosperidad, y para todas las mujeres, lesbianas, travestis, trans y varones del mundo que quieran habitar en el suelo argentino, invocando la fuerza de toda la razón y justicia, exigimos: jaborto legal ya!, jaborto legal ya!, jaborto legal ya!”

IX Recuperado de: https://cutt.ly/fd7SXpQ Fecha de consulta: 22 de enero de 2020.

Revista Zona Franca- Centro de estudios interdisciplinario sobre las mujeres (CEIM)- Maestría poder y sociedad desde la problemática de género (MG), Rosario, Argentina. ISSN, 2545-6504 http://zonafranca.unr.edu.ar/index.php/ZonaFrancal Número 28 (2020).

Página 35 
Mientras se enlazan las voces de mujeres que pronuncian con énfasis esta reversión feminista del preámbulo de la Constitución, con sus miradas enfocadas en el objetivo de la cámara que, en el fondo del plano, muestra el Parlamento intercalando materiales de archivo de la manifestación feminista durante el tratamiento del Proyecto en Diputados, suena un repiqueteo agitado de tambores, bombos y otros instrumentos de percusión que acentúan la idea de un tiempo que se acelera y vuelve inminente la llegada del día clave para la histórica lucha colectiva. La dirección emocional de esta pieza alcanza su apogeo cuando se muestra la emblemática imagen del grito de triunfo desahogado de la multitud captada desde lo alto del edificio en el momento en que se anunciaron por altoparlantes los resultados que condujeron a la media sanción.

La mirada panorámica que se inserta en el momento climático del audiovisual se encamina a acentuar el deseo por volver a repetir el triunfo. El plano general extenso, una elección formal que desde la teoría fílmica suele interpretarse como una apelación a la función descriptiva del discurso, consigue abrazar un espacio muy vasto gracias a la posición de la cámara alejada de los sujetos encuadrados. A diferencia de lo que sucede con el primer plano o con el plano-secuencia focalizando un fragmento del cuerpo femenino, para seguir el planteo de Mulvey (2007) sobre los placeres visuales del cine narrativo convencional $^{\mathrm{X}}$, que postula una relación predominantemente sexista entre imagen y mirada, se puede conjeturar que este video logra capturar el "rostro" -plural, colectivo- de la marea feminista.

\section{Pinceladas de humor y distensión}

x De acuerdo con Mulvey, en la situación cinemática convencional, el inconsciente masculino puede escapar a la angustia y la ansiedad de castración por medio de dos vías: el voyeurismo y la escopofilia fetichista. En el primer caso, se trata de una función de los instintos sexuales que separa la identidad erótica entre sujeto y objeto en la pantalla y se traduce en el placer de mirar a otro como objeto erótico. La mujer, circunscripta a una posición desvalorizada, aparece como quien debe ser salvada o castigada. En el segundo caso, se trata de una función de la libido del ego mediante la cual el yo se realiza a través de la identificación con el objeto de la pantalla, lo que implica la fascinación del espectador con la imagen.

Revista Zona Franca- Centro de estudios interdisciplinario sobre las mujeres (CEIM)- Maestría poder y sociedad desde la problemática de género (MG), Rosario, Argentina. ISSN, 2545-6504 http://zonafranca.unr.edu.ar/index.php/ZonaFranca| Número 28 (2020).

Página 36 
La red de trabajadoras de los medios audiovisuales de Argentina (MUA) se formó en 2017: "Queremos lograr la paridad de género en el ámbito laboral, fomentar el liderazgo y la presencia de las mujeres en los espacios de toma de decisión, además de alentar proyectos creativos de mujeres para expandir y enriquecer la forma en que participamos y somos representadas en todos los formatos de los medios globales", informan en su gacetilla ${ }^{\mathrm{Xl}}$. Este colectivo agrupa a mujeres que pertenecen a distintos rubros técnicos y artísticos (dirección, guión, edición, crítica, docencia). Emerge en un contexto en el que la industria del cine y los medios de comunicación se encuentran atravesados por la visibilización de reclamos y denuncias, a partir de fenómenos que adquirieron resonancia alrededor del mundo, tales como el \#MeToo entre las celebridades de Hollywood o las 82 femmes pour l'égalité encabezadas por Agnès Varda en el festival de Cannes de 2018.

Pese al énfasis de esta agrupación en lo audiovisual, han realizado una mayor cantidad de registros fotográficos, o bien, como se verá más adelante, participaron en coberturas mediáticas colaborativas. A los fines de recuperar algunas piezas comunicacionales en las que MUA intervino como coproductora o colaboradora en la difusión, que además permiten reconocer diversas estrategias discursivas, seleccionamos un corto de animación y un spot hecho junto con colectivos feministas y Mujeres Audiovisuales de todo el país (Emergentes, MUMA Neuquén, MUMA Bariloche, NUM Santiago del Estero, Mujeres Audiovisuales Rosario).

Varias de las apuestas visuales que venimos analizando a lo largo de este trabajo resultan innovadoras en cuanto a los procedimientos retóricos. No obstante, es por el juego de contrapuntos mediante el tratamiento del universo acústico que las piezas de comunicación de las acciones feministas adquieren mayor creatividad y fuerza persuasiva: cantos desobedientes, resonancias

XI Recuperado de: https://www.tiempoar.com.ar/nota/mujeres-audiovisuales-presentan-nosotrasmiramos Fecha de consulta: 22 de enero de 2020.

Revista Zona Franca- Centro de estudios interdisciplinario sobre las mujeres (CEIM)- Maestría poder y sociedad desde la problemática de género (MG), Rosario, Argentina. ISSN, 2545-6504 http://zonafranca.unr.edu.ar/index.php/ZonaFranca| Número 28 (2020). 
coloridas, pronunciamientos atronadores. En esta dirección, el 21 de julio MUA difundió un video de animación ${ }^{X I I}$ elaborado por Perro Fantasma (grupo musical rosarino que integran Pauline Fondevile y Federico Colombo) y Estefanía Clotti (ilustradora y realizadora audiovisual de Rosario), que está construido sobre una idea simple, basándose en el despliegue de un ethos de simpatía capaz de despertar sonrisas entre el público al que está destinado aprovechando el revival de consumos culturales del pasado (característico de la actual moda retro). En este caso, se trata de la invención de un videojuego (similar al Circus, al Pac Man o al Mario Bros) que evoca una memoria propia de la generación nacida en los setenta y en los ochenta. En lugar de la música original, pero emulando los sonidos electrónicos de estos pasatiempos, el personaje del videojuego hecho con lápices sobre un papel, como si fuese un dibujo infantil, va desplazándose hacia la derecha de la pantalla: a medida que sortea obstáculos (figurados por triángulos celestes $^{\mathrm{XIII}}$ ), suma puntos, por ejemplo, pasando por encima de una bandera de la diversidad sexual o acumulando pañuelos verdes, y así gana acompañantes, al compás de una de las melodías más paradigmáticas del cancionero feminista (que invoca la letra: "A la Iglesia Católica Apostólica Romana, que se quiere meter en nuestras camas, le decimos que se nos da la gana, de ser brujas, travestis y lesbianas. Aborto legal, en el hospital") $)^{\mathrm{XI}}$. Sin embargo, no deja de resultar llamativo que el juego sitúe un personaje masculino como protagonista de la gesta

XII Recuperado de: https://cutt.ly/ud7Aw0m Fecha de consulta: 22 de enero de 2020.

XIII Entre quienes se denominan a sí mismos "pro vida" -abarcando una franja social heterogénea en la que convergen posturas diversas-, ¿qué implicancias tiene la elección del celeste como principal sello identificatorio? En principio, así como el rosado es el color que acostumbran destinar a "las nenas", a "las mamás" o a las siluetas de "mujeres embarazadas", el celeste es para "el varón". Luego, el celeste remite a la bandera de la República Argentina, que junto con el escudo y la escarapela se incorpora a la iconografía del colectivo agrupado en torno a los lemas: "Salvemos las dos vidas", "Cuidemos las dos vidas", "Sí a la vida, no al aborto". En algunos casos, la cadena semántica que ata género y nación se hace explícita, pues el celeste remite al cielo patrio. Además, es el color del manto de la Virgen, que aparece en varias de las piezas gráficas de la franja que se opone a la legalización.

XIV Sobre el cancionero feminista desplegado por la Campaña Nacional por el Derecho al Aborto Legal, Seguro y Gratuito en la primera marcha Ni Una Menos en la Ciudad de Buenos Aires, véase Kratje (2016).

Revista Zona Franca- Centro de estudios interdisciplinario sobre las mujeres (CEIM)- Maestría poder y sociedad desde la problemática de género (MG), Rosario, Argentina. ISSN, 2545-6504 http://zonafranca.unr.edu.ar/index.php/ZonaFrancal Número 28 (2020).

Página 38 
animada que, en sus didácticas intenciones, pretendería combatir o sortear el androcentrismo.

"\#ConElla \#SeráLey, \#ConEl \#SeráLey, \#ConElle \#SeráLey, Al aborto lo ganamos en la calle": así es como se cierra otro video, difundido el 30 de julio de $2018^{X V}$, que propone un ensamble de respuestas, en palabras dichas por mujeres de edades y de lugares muy distintos, que van tramando una sucesión de voces que se relevan y enlazan para hablar de la tendencia del momento: ¿Por qué el verde? ¿Cómo lo usan? ¿Dónde se ponen el pañuelo? son preguntas tácitas que todas responden con ejemplos de su vida cotidiana y de sus vivencias unidas a la participación en marchas, manifestaciones, encuentros. El spot remarca la condición colaborativa de la producción, que luego se amplía en el Twit mediante los nombres de todxs Ixs intervinientes. Voces e imágenes con acentos regionales, voces de niñas, voces de jóvenes, voces de mujeres mayores, voces con la impostación de una locutora salen de las bocas y hablan también a través de los labios de otras contagiando entusiasmos en una urdimbre de experiencias:

"Elegimos el verde un poco sin querer. Para identificarnos. Lo sacábamos a la calle para las marchas, para los encuentros, y después volvía a casa. En todo: en la mochila, en la cabeza, de top, en la escuela, en la asamblea. Ya me olvidé de la cantidad de veces que regalé el que tenía, que me dicen: 'ey!, ¿dónde puedo conseguirlo?'. Yo ya sé que estoy en un buen lugar si veo otro pañuelo verde. Hay algo de complicidad, de que nos tenemos. Los voy contando, no los dejo de ver, no me canso. Son nuestros derechos, están en las calles. 'Ustedes, las del pañuelo verde, están en todas partes'. Estamos legitimando nuestra lucha. Aborto legal, seguro y gratuito".

Por un lado, entonces, el reclamo se configura desde una dimensión que destaca lo intergeneracional y el alcance federal, contrariamente a quienes

${ }^{x v}$ Recuperado de: https://cutt.ly/bd7SCkV. Fecha de consulta: 22 de enero de 2020.

Revista Zona Franca- Centro de estudios interdisciplinario sobre las mujeres (CEIM)- Maestría poder y sociedad desde la problemática de género (MG), Rosario, Argentina. ISSN, 2545-6504 http://zonafranca.unr.edu.ar/index.php/ZonaFranca| Número 28 (2020).

Página 39 
sostenían que en las provincias las mujeres no querían abortar. Por otro lado, el pañuelo que se regala opera como símbolo de traspaso generacional de la lucha.

\section{Ejemplificar y advertir}

El colectivo de Actrices Argentinas se formó en abril de 2018 al calor de los masivos reclamos por la legalización del aborto: "Siempre nos pronunciaremos en contra de un sistema que pretende tutelar nuestros cuerpos al obligarnos a inscribir los mismos en el orden simbólico de la maternidad, más allá de nuestra voluntad y deseo", afirmaron ${ }^{X V 1}$. Dolores Fonzi, Muriel Santa Ana, Nancy Duplaá, Cecilia Roth, Verónica Llinás, Griselda Siciliani, Jazmín Stuart, Carla Peterson, Lali Espósito, Florencia de la V, Eleonora Wexler, Julieta Ortega, Julieta Zylberberg, Violeta Urtizberea, Alejandra Flechner, Bárbara Lombardo, Cecilia Dopazo, Julieta Cardinali, Julieta Díaz son algunas de sus integrantes. La agrupación adquirió notoriedad al ocuparse de visibilizar el acoso sexual y el maltrato dentro de sus ámbitos laborales; en particular, cuando en diciembre de ese año apoyaron la denuncia de Thelma Fardín contra el galán abusador Juan Darthés. Por tratarse de figuras que frecuentan la pantalla televisiva, las actrices cuentan con un extenso reconocimiento del público a nivel nacional, que es utilizado en la mayoría de las piezas comunicacionales generadas por el colectivo.

En tal sentido, hay dos series que nos interesa destacar, donde se aprovecha su reconocimiento público para intentar persuadir a los y a las representantes de votar por la legalización del aborto y para transmitir la importancia de concurrir a las manifestaciones. Por una parte, las producciones que difundieron a finales de julio y principios de agosto, dirigiéndose de forma directa y frontal a Senadores y Senadoras que, o bien no habían revelado cuál

XVI Recuperado de: https://cutt.ly/Fd7P6gi Fecha de consulta: 22 de enero de 2020.

Revista Zona Franca- Centro de estudios interdisciplinario sobre las mujeres (CEIM)- Maestría poder y sociedad desde la problemática de género (MG), Rosario, Argentina. ISSN, 2545-6504 http://zonafranca.unr.edu.ar/index.php/ZonaFrancal Número 28 (2020). 
sería su voto, o bien se pronunciaron en contra ${ }^{X V I I}$. Por otra parte, los numerosos videos caseros que divulgaron el día previo al tratamiento de la Ley en la Cámara Alta para alentar la concurrencia a la plazaXVIII: "El 8 de agosto llenamos las calles, estamos en todas las plazas del país, Senadores: honren la media sanción de Diputados, que sea ley, será ley". A través de breves comunicados grabados por actrices y por algunos actores, se dirigen a miembros del Senado personalidades como Graciela Borges, Jazmín Stuart, Julieta Zylberberg, Mercedes Morán, Carola Reyna, Muriel Santa Ana, Verónica Lozano, Romina Ricci, Catherine Fulop, Esteban Lamothe, Cristina Banegas, Martín Slipak, Nancy Dupláa, Julieta Cardinale, entre otras. Las grabaciones, que no están firmadas porque suponen el amplio reconocimiento de las y los convocantes, se difundieron desde la cuenta de Twitter de esta agrupación.

La interpelación frontal al auditorio y el tono de confrontación son dos características presentes en los videos emitidos desde las redes de Actrices Argentinas los días 31 de julio, 1 de agosto y 3 de agosto, donde se dirigen a representantes de las Provincias de Catamarca, de Formosa y de Tucumán ante la inminente votación en el Senado de la Nación, una cámara harto conocida por su recalcitrante composición conservadora. Cada comunicado, de menos de un minuto, se basa en el registro de actrices conocidas a nivel nacional portando pañuelos verdes, quienes hablan a cámara con énfasis que van del enojo y el reto (incluyendo el gesto del dedo acusador como si le estuvieran hablando a una criatura a quien se increpa, explicándole los motivos de su disgusto) hasta el pedido con expresión suplicante de votar por la legalización. Los enunciados increpan con nombre y apellido a determinados/as Senadores y Senadoras. Se

\footnotetext{
XVII Recuperado de: https://cutt.ly/sd7P8RP Fecha de consulta: 22 de enero de 2020. Recuperado de: https://cutt.ly/Wd7P3nN Fecha de consulta: 22 de enero de 2020. Recuperado de: https://cutt.ly/Ed7P93f Fecha de consulta: 22 de enero de 2020. XVIII Recuperado de: https://cutt.ly/hd7P9ws Fecha de consulta: 22 de enero de 2020. Recuperado de: https://cutt.ly/td7P2ld Fecha de consulta: 22 de enero de 2020. Recuperado de: https://cutt.Iy/Ud7P0JI Fecha de consulta: 22 de enero de 2020. Recuperado de: https://cutt.ly/wd7P0jD Fecha de consulta: 22 de enero de 2020. Recuperado de: https://cutt.ly/sd7PB8S Fecha de consulta: 22 de enero de 2020.
}

Revista Zona Franca- Centro de estudios interdisciplinario sobre las mujeres (CEIM)- Maestría poder y sociedad desde la problemática de género (MG), Rosario, Argentina. ISSN, 2545-6504 http://zonafranca.unr.edu.ar/index.php/ZonaFrancal Número 28 (2020). Página 41 
mencionan datos de cada situación provincial respecto de la falta de educación sexual, la clandestinidad del aborto y los embarazos no deseados. Para reforzar los reclamos, intercaladas con las grabaciones de las actrices se incluyen capturas fotográficas de la prensa que convalidan la petición. La música redunda en la construcción de un clima de gravedad. De hecho, estas piezas adquieren un tono de denuncia en el que se compendia la estética televisiva de los programas de opinión, al presentar breves informes audiovisuales con los ejes de discusión del momento y al desarrollar el debate crispado en un estudio donde los y las participantes ponen en escena sus argumentos montando una escena de diálogo pour la galerie.

En este punto, surgen interrogantes acerca de la potencia persuasiva de este tipo de piezas. Se trata de videos que nombran y enfocan a destinatarios/as puntuales, pero que fueron ampliamente difundidos para que toda la ciudadanía, en primer lugar, reconociera al colectivo de las actrices (de formación reciente en aquel momento) $y$, en segundo lugar, para que propagase estos comunicados a través de las redes a fin de presionar a los y a las representantes. Se podría afirmar que Actrices Argentinas se ampara en dos fuentes de legitimación para otorgar visibilidad a las demandas del movimiento de mujeres: la fama y el pañuelo verde. Desde ese lugar, enuncian los encabezados de los videos:

"ATENCIÓN CATAMARCA!!! Catamarca tiene una de las tasas más altas de delitos sexuales, una tasa de embarazo adolescente altísima y no adhiere a la Ley de Aborto por causales. ¡Protejan a las mujeres! Están a tiempo.

¡¡ATENCIÓN FORMOSA!! Senador Naidenoff, gracias por proteger a las mujeres con su voto. Senadora Gonzales, Senador Mayans: honren su cargo legitimando nuestro derecho a la salud. Maduremos como país. Hagan historia.

Revista Zona Franca- Centro de estudios interdisciplinario sobre las mujeres (CEIM)- Maestría poder y sociedad desde la problemática de género (MG), Rosario, Argentina. ISSN, 2545-6504 http://zonafranca.unr.edu.ar/index.php/ZonaFrancal Número 28 (2020). 


\begin{abstract}
¡¡ATENCIÓN TUCUMÁN!! La senadora Mirkin está a favor de la salud de las mujeres. Senadora Elias de Pérez, Senador Alperovich, abran paso para subsanar la realidad del aborto en Argentina. No perpetúen la clandestinidad. \#AbortoLegalYa \#8A a la calle!!"
\end{abstract}

Tal como se lee, predomina un tono pedagógico cuya meta es instruir a los y las representantes del Senado para que recapaciten: "Gobernador Mera, usted no cree que haya que penalizar a una mujer que decide abortar, pero sin embargo está en contra del aborto legal, seguro y gratuito. Entonces: ¿cómo va a resolver el problema del negocio clandestino en su Provincia que pone en riesgo la salud de nuestras mujeres?". Se trata de preguntas que adquieren un tono agresivo en el que resuena la modalidad del escrache público. En esta línea, Actrices Argentinas divulgó a través de su cuenta de Twitter una filmación casera inmediatamente posterior a que se conociera el rechazo del Senado, en el que hablan a cámara enojadas desplegando un discurso francamente amenazador (en tal sentido, semejante a la forma que adopta la presión que la Iglesia efectivamente ejerció sobre el Estado). En cambio, en intervenciones mancomunadas con La Campaña, se siguen otras coordenadas (por ejemplo, la apostasía colectiva que realizaron frente a la Catedral Metropolitana el 15 de septiembre de 2018). Esta mirada comparativa permitiría señalar que el recurso a la acusación respaldada en la imagen mediática de las actrices (en tanto imagos) pretende interpelar a su auditorio actualizando un tono característico del entorno mediático de las discusiones entre famosxs o panelistas. En contraste, cuando unen su carisma y su militancia a la fuerza histórica del movimiento feminista logran articular un discurso menos restringido, es decir, en una forma que,en lugar de posicionarlas como juezas que acusan o defienden con base a lo que consideran justo o injusto, redunde en un mayor vuelo creativo propiciando la confluencia de la experiencia y la memoria feminista con la expansión del alcance de los mensajes hacia un sector de la sociedad que tal vez no conoce las acciones

Revista Zona Franca- Centro de estudios interdisciplinario sobre las mujeres (CEIM)- Maestría poder y sociedad desde la problemática de género (MG), Rosario, Argentina. ISSN, 2545-6504 http://zonafranca.unr.edu.ar/index.php/ZonaFrancal Número 28 (2020).

Página 43 
"Que sea ley". Producciones audiovisuales colaborativas en torno a la Campaña Nacional por el Derecho al Aborto Legal, Seguro y Gratuito

de La Campaña pero sí reconoce a las figuras que se erigen como portavoces y protagonistas de las demandas.

\section{Voces y actuaciones en primera persona}

Para terminar este recorrido retomamos la producción colaborativa: "Relatos basados en testimonios reales", una serie realizada por La Campaña junto con Actrices Argentinas y Mujeres Audiovisuales de Argentina, que consiste en once videos, de dos minutos y medio de duración cada uno, difundidos entre mayo y julio de 2018. Estos videos ${ }^{\mathrm{XIX}}$ inician con una secuencia en la que se introducen susurros que conforman un colchón sonoro donde se superponen confesiones que traman varias capas de voces para dejar oír fragmentos de experiencias de abortos realizados en la clandestinidad: "aborté con misoprostol", "en una clínica", "aborté en mi casa", "tenía miedo", "estaba sola", "con mi marido", "sangré diez días". En simultáneo, las imágenes enfocan el rostro de mujeres de diferentes edades que miran a cámara de frente, sin mover los labios. Se trata, pues, de voces no sincronizadas que se independizan de los cuerpos multiplicando sus resonancias. Siguiendo las reflexiones de Kaja Silverman (1988) acerca de la intersección de la mirada y la voz en el cine narrativo convencional, donde la perfecta sincronización sirve para encadenar la materialidad de la voz al cuerpo de las mujeres (a diferencia de las posibilidades que se suelen otorgar a las voces masculinas para trascender el cuerpo e investirse como fuente autorizada por sobre lo que se ve), este video vuelve audible aquello que estuvo mucho tiempo oculto, silenciado, relegado a relatos íntimos, que sólo puede circular como un secreto, dicho por lo bajo, entre mujeres. Las murmuraciones, el conventilleo, como dice María Moreno (2018), son tácticas del débil. "Estaba segura", enuncian tres veces, y en ese momento el plano muestra las manos de dos mujeres agarrándose con firmeza. Sobre un fondo negro, varias actrices reconocidas, que visten también de negro, aparecen encuadradas de frente. Una de ellas,

XIX El video que aquí comentamos, del 21 de mayo de 2018, se titula: "SOMOS HISTORIAS I Relato de aborto en primera persona, por Cecilia Roth". Recuperado de: https://www.youtube.com/watch?v=uq2sElaea5s. Fecha de consulta: 22 de enero de 2020.

Revista Zona Franca- Centro de estudios interdisciplinario sobre las mujeres (CEIM)- Maestría poder y sociedad desde la problemática de género (MG), Rosario, Argentina. ISSN, 2545-6504 http://zonafranca.unr.edu.ar/index.php/ZonaFrancal Número 28 (2020). 
ubicada en el centro, da unos pasos hacia adelante. Sobre la pantalla se imprime el texto "Lorena, 30 años". La actriz relata una historia que, a su vez, aparece subtitulada:

"Lucrecia tenía 39 y una hija de 4 años. Era la hermana de mi mamá, mi tía. Una mañana de un 5 de julio llamaron a mi madre a la pensión para decirle que Lucrecia estaba muy mal, que fuera urgente a verla. Decidieron llevarla al Hospital Muñiz, donde la revisaron y le dijeron a mi mamá que tenía una septicemia. Después entró un policía a la habitación y mi mamá le dijo que no lo quería ahí, que se fuera, que mi tía no se iba a escapar, que se iba a morir. Nunca le dijeron a mi mamá el por qué de la infección, pero ella dice que escuchó a una enfermera diciéndole a Lucrecia: ‘¿Qué te hiciste, nena? ¿Usaste perejil?' Lucrecia fue velada durante nueve días, con rezos, como se hacía en Formosa. Ella murió el 13 de julio de 1968."

Un fundido a negro desvanece el rostro de la actriz. En el cuadro siguiente, en mayúscula y con una tipografía de palo seco que resalta las letras blancas impresas sobre un fondo verde, se puede leer: "El aborto legal salva vidas". La crudeza de los testimonios adquiere mayor relieve por la ausencia de música incidental. Mediante un tratamiento estilizado, con operaciones de ficcionalización en cuanto al trabajo actoral, se documentan historias que atraviesan geografías y décadas. La sororidad y la empatía se desarrollan con un ethos de franqueza que destaca la importancia de su legalización basando el argumento en hechos reales, puesto que se trata de elegir entre la clandestinidad o la regulación.

\section{Consideraciones finales: palabras e imágenes encarnadas}

Al inicio del trabajo señalamos que la producción audiovisual forma parte del contexto discursivo de las movilizaciones que tuvieron lugar en distintos puntos del país y se concentraron frente al Congreso. A lo largo de estas páginas, observamos que algunos audiovisuales apelan a relatos (orales o escritos) de experiencias que exponen la crudeza de los abortos practicados en condiciones clandestinas, con el objetivo de persuadir a los sectores no convencidos o de

Revista Zona Franca- Centro de estudios interdisciplinario sobre las mujeres (CEIM)- Maestría poder y sociedad desde la problemática de género (MG), Rosario, Argentina. ISSN, 2545-6504 http://zonafranca.unr.edu.ar/index.php/ZonaFrancal Número 28 (2020).

Página 45 
polemizar con quienes se oponen a su legalización recurriendo tanto a la primera persona como a narraciones en tercera persona. Más que hablar desde la vivencia intransferible o desde una posición omnisciente, la presencia del cuerpo, de las palabras y de la voz en la pantalla describiendo y rememorando experiencias refuerza los lazos de conexión entre las mujeres: por caso, una actriz narra un hecho sin que importe si le sucedió efectivamente a ella, mediante procedimientos de ficcionalización que buscan generar empatía. El razonamiento inductivo, que subyace en esta serie de piezas comunicacionales, apunta al enlace de historias que conectan a todas, más allá de las diferencias y de las desigualdades: las particularidades de un caso relatado por una figura renombrada de la cultura mediática opera de modo ejemplar que apunta a lograr una interpelación universal. En otros casos, se recurre a figuras de autoridad provenientes de campos profesionales que jerarquizan el saber medicinal y el saber jurídico desplegando razones y pasiones a todas luces opuestas al miedo y a la culpa que se pretenden infundir desde los escraches o desde las amenazas por parte de grupos fundamentalistas. Algunos argumentos aparecen infundidos con tonos de franqueza y de seriedad; otros, en cambio, ofrecen una réplica de los mensajes conservadores por medio del sentido del humor, el desparpajo, la ironía, haciendo un uso lúdico y político del arte de la retórica audiovisual.

No hay dudas de que el cuerpo es un territorio en disputa que los colectivos feministas se ocupan de figurar como tal, aun sin la necesidad de apoyarse en palabras. Se pone el foco en la autonomía y en la decisión individual (por ejemplo, en pancartas con ilustraciones de las trompas de Falopio como si fuesen el manubrio de una bicicleta visto de frente) y en la libertad de elección al expresar el reclamo mediante la actualización de una atmósfera festiva, alegre, carnavalesca (con sonoridades rotundamente disímiles al rap cristiano y a las cadenas de rezos o de llantos profesados por sectores religiosos contrarios a la legalización). En este punto, a partir de los videos indagados, podemos afirmar que la multiplicidad y la diversificación de los enunciados a favor de la interrupción voluntaria del

Revista Zona Franca- Centro de estudios interdisciplinario sobre las mujeres (CEIM)- Maestría poder y sociedad desde la problemática de género (MG), Rosario, Argentina. ISSN, 2545-6504 http://zonafranca.unr.edu.ar/index.php/ZonaFrancal Número 28 (2020).

Página 46 
embarazo es un signo de la libertad de expresión que envuelve a quienes se identifican con la amplia marea feminista. Mujeres y jóvenes, en suma, quienes en mayor medida salieron a la calle a manifestarse por el derecho al aborto y que se valen de sus redes sociales como caja de resonancia de sus posiciones éticas y políticas no tienen su discurso atado a pautas expresivas prefijadas o reguladas por la obligación de acatar a una autoridad, debido a que no hay "bajadas de línea" que restrinjan su rango de acción y de comunicación.

La fuerza que el reclamo en favor del aborto ha tomado en los últimos años enseña las raíces profundas del movimiento de mujeres en la Argentina, que dan sustento a las luchas del presente (Barrancos, 2010; Chejter, 1996; Alma y Lorenzo, 2009; Tarducci, Trebisacce y Grammático, 2019). El papel de las redes sociales, en este marco, permite al activismo feminista aprovechar sus circuitos para dar nuevas formas a las demandas en favor de la ampliación de derechos y diseminarlas. En este trabajo hemos buscado ponderar, justamente, desafíos y alcances de las redes sociales para la construcción de sentidos que se disputan horizontes emancipadores y vitales para las mujeres. La heterogeneidad de los materiales audiovisuales producidos por la Campaña Nacional por el Derecho al Aborto Legal, Seguro y Gratuito y diferentes grupos que apoyaron el reclamo permite observar las múltiples estrategias persuasivas respecto de la interpelación del público que está a favor, en contra, o bien se plantea como indeciso. En la mayoría de los casos, la persuasión se apoya en argumentos que encuentran sustento en datos científicos, en estadísticas, en testimonios, en experiencias cuya capacidad de conmover y de convencer ilumina el compromiso personal y político del colectivo de mujeres para luchar por su autonomía.

\section{Bibliografía}

ALMA, Amanda y LORENZO, Paula (2009). Mujeres que se encuentran. Una recuperación histórica de los Encuentros Nacionales de Mujeres en Argentina (1986-2005). Buenos Aires: Feminaria.

Revista Zona Franca- Centro de estudios interdisciplinario sobre las mujeres (CEIM)- Maestría poder y sociedad desde la problemática de género (MG), Rosario, Argentina. ISSN, 2545-6504 http://zonafranca.unr.edu.ar/index.php/ZonaFranca| Número 28 (2020).

Página 47 
ANZORENA, Claudia y ZURBRIGGEN, Ruth (2013). "Trazos de una experiencia de articulación federal y plural por la autonomía de las mujeres: La Campaña Nacional por el Derecho al Aborto Legal, Seguro y Gratuito en Argentina" en Claudia Anzorena y Ruth Zurbriggen (eds.), El aborto como derecho de las mujeres. Otra historia es posible. Buenos Aires: Herramienta, pp. 17-38.

BARRANCOS, Dora (2010). Mujeres en la sociedad argentina. Una historia de cinco siglos. Buenos Aires: Sudamericana.

BELLUCCI, Mabel (2014). Historia de una desobediencia. Aborto y Feminismo. Buenos Aires: Capital Intelectual.

BARTHES, Roland (1972). Investigaciones retóricas. Buenos Aires: Tiempo Contemporáneo.

CHEJTER, Silvia (1996). "Feminismo por feministas", Travesías, Año 4, № 5.

DE LAURETIS, Teresa (1992). Alicia ya no. Feminismo, Semiótica, Cine. Madrid: Cátedra.

DE LAURETIS, Teresa (1996). "La tecnología del género", Mora, № 2, pp. 6 34.

DURAND, Teresa y GUTIERREZ (1998). "Tras las huellas de un porvenir incierto: del aborto a los derechos sexuales y reproductivos" en VV.AA., Avances en la Investigación Social en Salud Reproductiva y Sexual. Buenos Aires: AEPA, CEDES, CENEP, pp. 281-302.

ELIZALDE, Silvia y MATEO, Natacha (2018). "Las jóvenes: Entre la 'marea verde' y la decisión de abortar", Salud Colectiva, Vol.14, N³, pp. 433-446.

KUHN, Annette (1991). Cine de mujeres. Feminismo y cine. Madrid: Cátedra.

KRATJE, Julia (2016). "De boca en boca", Invisibles. Recuperado de: http://www.revistainvisibles.com/De-Boca-En-Boca-Por-Julia-Kratje.Html

LAUDANO, Claudia (2012). "Reflexiones en torno a las imágenes fetales en la esfera pública y la noción de 'vida' en los discursos contrarios a la legalización del aborto", Temas de Mujeres, Año 8, № 8, pp. 57-69. Recuperado de: http://ojs.filo.unt.edu.ar/index.php/temasdemujeres/article/view/60/60

Revista Zona Franca- Centro de estudios interdisciplinario sobre las mujeres (CEIM)- Maestría poder y sociedad desde la problemática de género (MG), Rosario, Argentina. ISSN, 2545-6504 http://zonafranca.unr.edu.ar/index.php/ZonaFranca| Número 28 (2020). 
LAUDANO, Claudia (2018). "Aborto y redes: el debate por \#AbortoLegal", Sociales en Debate, № $14 . \quad$ Recuperado de: https://publicaciones.sociales.uba.ar/index.php/socialesendebate/article/view/3350/ $\underline{2747}$

LAUDANO, Claudia y KRATJE, Julia (2018). "Vivas y libres nos queremos', 'Nosotras paramos'. Una cartografía de producciones audiovisuales en torno al primer paro internacional de mujeres", Millcayac, Vol. 5, № 9, pp. 377396. Recuperado de:http://revistas.uncu.edu.ar/ojs/index.php/millcadigital/article/view/1368/900

MORENO, María (2018). "Conventillear", Panfleto: Erótica y Feminismo. Random House: Buenos Aires, pp. 225-230.

MULVEY, Laura (2007). "El placer visual y el cine narrativo", Cordero, K. y Sáenz, I. (comps.), Crítica feminista en la teoría e historia del arte. México: Universidad Iberoamericana.

POLLOCK, Griselda (2013). "Intervenciones feministas en las historias del arte", Pollock, G. (ed.), Visión y diferencia. Feminismo, feminidad e historias del arte. Buenos Aires: Fiordo, pp. 19-50.

SILVERMAN, Kaja (1988). The Acoustic Mirror. The Female Voice in Psychoanalysis and Cinema. Bloomington: Indiana University Press.

SUTTON, Barbara (2020). "Intergenerational Encounters in the Struggle for Abortion Rights in Argentina", Women's Studies International Forum 82:102392.

TARDUCCI, Mónica, TREBISACCE, Catalina y Karin GRAMMATICO (2019). Cuando el feminismo era mala palabra. Algunas experiencias del feminismo porteño. Buenos Aires: Espacio Editorial.

Revista Zona Franca- Centro de estudios interdisciplinario sobre las mujeres (CEIM)- Maestría poder y sociedad desde la problemática de género (MG), Rosario, Argentina. ISSN, 2545-6504 http://zonafranca.unr.edu.ar/index.php/ZonaFrancal Número 28 (2020). 